\title{
Diversidad de inclusiones minerales en la subtribu Oncidiinae (Orchidaceae)
}

\author{
Estela Sandoval-Zapotitla ${ }^{1}$, Teresa Terrazas ${ }^{2}$ \& José Luís Villaseñor ${ }^{2}$
}

1. Jardín Botánico, Instituto de Biología, Universidad Nacional Autónoma de México. Avenida Universidad 3000, Ciudad Universitaria, C.P. 04510, Distrito Federal, México; esz@ibiologia.unam.mx

2. Departamento de Botánica, Instituto de Biología, Universidad Nacional Autónoma de México. Avenida Universidad 3000, Ciudad Universitaria, C.P. 04510, Distrito Federal, México.

Recibido 06-VIII-2009. Corregido 09-I-2010. Aceptado 02-II-2010.

\begin{abstract}
Diversity of mineral inclusions in the subtribe Oncidiinae (Orchidaceae). Mineral inclusions in plants, of different chemical constitution and forms, have been studied in some plant groups and are currently used as diagnostic tools in taxonomic identifications. With the aim to identify their possible application in taxonomy, mineral inclusions in the leaves of 140 species of Oncidiinae (Orchidaceae) were analyzed and compared. Leave transversal sections were studied with the aid of clear field, phase contrast, and polarized light microscopy. Crystals commonly occured in mesophyll cells, and only in two species those were observed in epidermal cells. Several forms of calcium oxalate crystals and silicdioxide deposits in the form of stegmata were found. The most common crystalline forms were raphides, prisms and druses. Nevertheless, crystals like sands, and concentric and radial plates were also observed in few species. These crystalline forms of concentric and radial plates are reported for the first time in Oncidiinae and Orchidaceae. The stegmata are conical with rough surface, forming tiers along with fibers. Stegmata commonly occur in the vascular bundle sheath and in the abaxial or adaxial fiber bundles. However, few species do not have stegmata in fiber bundles and other species lack both. The taxonomic importance of these mineral inclusions is discussed for the different clades, genera or species within the subtribe Oncidiinae. Rev. Biol. Trop. 58 (2): 733-755. Epub 2010 June 02.
\end{abstract}

Key words: leaf, crystals, calcium oxalate, raphides, silica, stegmata, Orchidaceae, Oncidiinae.

Las plantas por lo general presentan en algunas de sus células inclusiones minerales, como cuerpos de sílice o cristales de diversa naturaleza. En cerca del $75 \%$ de las angiospermas los cristales de oxalato de calcio son los más abundantes y ampliamente distribuidos (Franceschi \& Horner 1980, Horner \& Wagner 1995, Franceschi \& Nakata 2005). Independiente de su naturaleza, los cristales aparecen en una variedad de formas como rafidios, estiloides, drusas, prismas y arena; su constancia entre las especies es de relevancia taxonómica (Prychid \& Rudall 1999, Webb 1999, Franceschi \& Nakata 2005).

En las hojas, los cristales se forman de manera intracelular o extracelular en el mesófilo; sin embargo, también se reportan cristales epidérmicos (Prychid \& Rudall 1999). Los rafidios, por ejemplo, están presentes en la mayoría de las monocotiledóneas (Prychid \& Rudall 1999). Particularmente en las Orchidaceae, los rafidios son los cristales más comunes y a menudo se les puede encontrar al mismo tiempo con otras formas cristalinas, como drusas (Carlsward et al. 1997) o prismas (Stern et al. 1993). La presencia, ausencia o ubicación de las diferentes formas de cristales pueden ser de utilidad taxonómica (Carlsward et al. 1997, Lersten \& Horner 2000, Cervantes 2009).

Los contenidos minerales de sílice se presentan en diversos órganos de las angiospermas (Møller \& Rasmussen 1984, Hodson et 
al. 2005). Existen varias formas morfológicas de contenidos minerales de sílice o cuerpos de sílice y su número por célula puede variar. Las formas más comunes de cuerpo de sílice son el tipo esférico de drusa, nodular, rugoso o espinoso. Otras formas de cuerpos de sílice incluyen el tipo de cono truncado, de batea y de arena. Algunas de estas formas son consistentes dentro de Cymbidium (Cyrtopodiinae) o dentro de las tribus Cymbidieae y Maxillarieae en Orchidaceae (Yukawa \& Stern 2002) y pueden utilizarse a modo de caracteres diagnósticos, como un apoyo en la identificación de sus miembros (Hodson et al. 2005). La localización relativa de los cuerpos de sílice en las plantas también es variable; se pueden localizar en las células epidérmicas o pueden estar sobre las paredes externas de las células de la vaina esclerótica de los haces vasculares y no vasculares (Prychid et al. 2004). En particular, los cuerpos de sílice presentes en células asociadas al esclerénquima reciben el nombre de estégmatos. Hasta donde se sabe, los estégmatos están restringidos a unas cuantas familias de monocotiledóneas, como Arecaceae, Marantaceae, Musaceae, Orchidaceae, Restionaceae y Zingiberaceae (Møller \& Rasmussen 1984).

La presencia de estégmatos en Orchidaceae fue reportada por primera vez por Solereder \& Meyer (1930) y actualmente se han registrado en cuatro de sus seis subfamilias; sin embargo, algunas especies no los presentan (Stern 1997a, Stern 1997b, Stern \& Judd 2001, Prychid et al. 2004). Los estégmatos se encuentran sobre las fibras de los haces vasculares o no vasculares, tanto en las hojas como en el tallo, y están ausentes en la epidermis (Davies 1999).

La subtribu Oncidiinae (Subfamila Epidendroideae, tribu Maxillarieae), con aproximadamente 95 géneros y 1700 especies (Williams et al. 2001a, 2001b) es considerada una de las más derivadas dentro de las Orchidaceae (Dressler 1993, Sosa et al. 2001, Williams et al. 2001a, 2001b). Los miembros de esta subtribu son especies típicamente epífitas, unas cuantas son terrestres o litófitas; se les encuentra desde el nivel del mar hasta los páramos de alta montaña, desde Sinaloa y Tamaulipas en México hasta
Misiones en Argentina, pasando por el extremo sur de Perú, así como a través del Caribe, incluyendo el sur de Florida en Estados Unidos (Chase \& Palmer 1988). Williams et al. (2001a, 2001b), en un análisis con datos moleculares (ITS, matK, trnF-L), reconocen diez clados principales; Sandoval-Zapotitla et al. (en prensa) a partir de un análisis cladístico combinado, incluyendo datos moleculares, anatómico-foliares y morfológicos, reconocen nueve de los diez clados previamente identificados para Oncidiinae. En el presente trabajo se considera que los contenidos minerales pueden proporcionar caracteres potencialmente útiles para caracterizar los clados reconocidos para Oncidiinae y apoyar sus relaciones filogenéticas. Los objetivos son los siguientes: describir y comparar las inclusiones minerales de las hojas de 140 especies de Oncidiinae; y, determinar si su presencia, forma y ubicación, tienen valor diagnóstico para apoyar la caracterización y relación de los clados propuestos para Oncidiinae.

\section{MATERIALES Y MÉTODOS}

Con base en los trabajos de Williams et al. (2001a, 2001b) y Sandoval-Zapotitla et al. (en prensa), se seleccionaron 140 especies de Oncidiinae que representan los principales clados propuestos para Oncidiinae (Apéndice 1). Para facilitar la descripción de los resultados, en adelante se adoptarán las mismas letras asignadas a los clados por Sandoval-Zapotitla et al. (en prensa). Los nombres de las especies siguen las propuestas de nomenclatura más recientes (Soto et al. 1993, Dressler \& Williams 2003, Williams et al. 2001a, Chase et al. 2008, Chase et al. 2009). Los ejemplares que respaldan las observaciones para cada especie se presentan en el Apéndice 1. A una hoja madura de cada especie se le cortó una fracción de la región media de la lámina. Estas fracciones fueron fijadas en Navashin, deshidratadas en alcohol ter-butílico (ATB), infiltradas e incluidas en parafina histológica $\left(58-60^{\circ} \mathrm{C}\right)$ y cortadas en micrótomo de rotación para obtener secciones transversales de 15-20 $\mu \mathrm{m}$. Estas secciones fueron teñidas con safranina-verde rápido $\mathrm{y}$ 
montadas con resina sintética como preparaciones permanentes (Sandoval-Zapotitla et al. 2005). Adicionalmente, fracciones de hoja de $1 \mathrm{~cm}$ de ancho se transparentaron con hidróxido de sodio al $20 \%$ y posteriormente con hipoclorito de sodio al $20 \%$, se montaron como preparaciones con gelatina glicerinada, y se utilizaron para corroborar los contenidos minerales. Todas las preparaciones fueron rotuladas y depositadas en la colección biológica del Laboratorio de Apoyo a la Investigación del Jardín Botánico, Instituto de Biología, Universidad Nacional Autónoma de México.

Las secciones fueron observadas y examinadas en un fotomicroscopio de luz Carl Zeiss Axioskope. Las propiedades de birrefringencia de las inclusiones minerales fueron utilizadas para detectar su presencia a través de las técnicas de iluminación de campo claro, contraste de fases y polarización (Rincón \& Reyes 1991, Barrera \& Cárdenas 1997, Vovides 1999, Sandoval-Zapotitla et al. 2005). Asimismo, para cada especie se registró la forma y ubicación del contenido mineral en la hoja. Las imágenes seleccionadas fueron capturadas digitalmente usando el mismo fotomicroscopio, editadas en Paint Shop Pro 8.0 y organizadas en las láminas. Con el propósito de conocer si el número de estratos de haces de fibras abaxiales que desarrollan las especies determina la presencia de los estégmatos, se hizo un análisis de correlación de Spearman, que permitió conocer si existe relación entre el número de estratos de haces de fibras abaxiales y el número de especies que tienen estégmatos asociados a estas fibras.

\section{RESULTADOS}

Cristales: Las 140 especies estudiadas de Oncidiinae (sensu Williams et al. 2001a, 2001b) tienen rafidios, ubicados principalmente hacia los márgenes de la lámina en el mesófilo; sin embargo, la cantidad de rafidios por célula y su tamaño relativo varía entre las especies (Fig. 1). Sólo 70 especies contienen al menos otra forma cristalina más, como

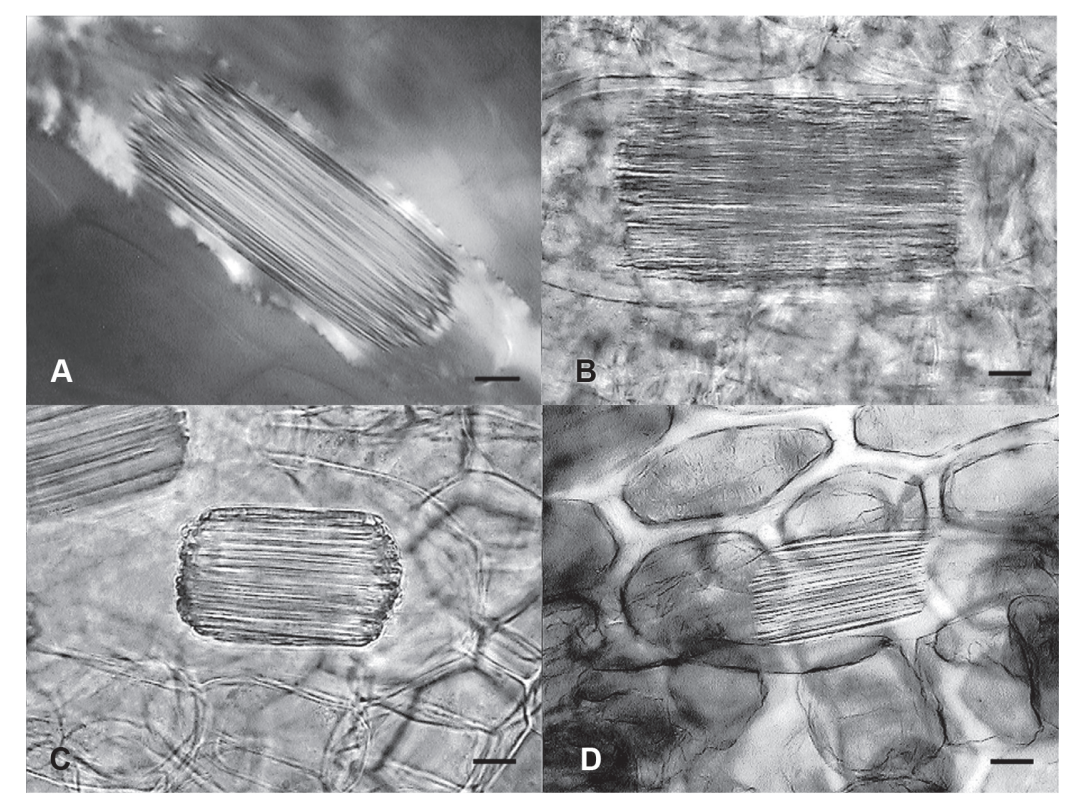

Fig. 1. Rafidios en Oncidiinae. Vista superficial. A. Oncidium fimbriatum, con luz polarizada. B. Mesospinidium panamense, campo claro. C. Macroclinium bicolor, campo claro. D. Cuitlauzina pygmaea, campo claro. Barras=1 $\mu \mathrm{m}$.

Fig. 1. Raphides in Oncidiinae. Front view. A. Oncidium fimbriatum with polarized light. B. Mesospinidium panamense, bright field. C. Macroclinium bicolor, bright field. D. Cuitlauzina pygmaea, bright field. Bars $=1 \mu \mathrm{m}$. 
prismas, drusas, arena o formas no definidas en la literatura (Fig. 2A; Cuadro 1). Las formas cristalinas en Oncidiinae se localizan en las células parenquimáticas del mesófilo, en Cuitlauzina pygmaea (Lindl.) M.W.Chase \& N.H.Williams están sólo en las células epidérmicas y en Rossioglossum ampliatum (Lind.) M.W.Chase \& N.H.Williams, en ambos tipos de células (Cuadro 1).

Los prismas son la segunda forma más común de cristal (Fig. 2A). Se les observó en 62 especies que representan 22 géneros (Cuadro 1) y el $44.3 \%$ de las especies incluidas. Los prismas están distribuidos en siete de los diez clados estudiados. Los clados con mayor porcentaje de especies que contienen prismas son el E y el F, y los de menor son el B y el G; los clados A, C y D no tienen prismas (Fig. 2B). Oncidium hymenanthum (Schltr.) M.W.Chase $\&$ N.H.Williams (clado E) es la única especie con cristales prismáticos distintivos respecto al resto de las especies estudiadas (Fig. 3A).

Las drusas se observaron en 33 especies de los géneros Aspasia, Miltonia, Notyliopsis y Oncidium (Fig. 3B, 3C; Cuadro 1), que correspondieron al $23.6 \%$ de las especies evaluadas (Fig. 2A) y seis de los diez clados estudiados. El clado con mayor porcentaje de especies condrusas es el E y el de menor es el $\mathrm{H}$; los clados A, B, C y D no tienen drusas (Fig. 2C).

Las arenas se observaron exclusivamente en Aspasia epidendroides Lindl., Cuitlauzina pygmaea, Miltonia spectabilis Lindl., Oncidium uniflorum Booth ex Lindl., O. warminhii Rchb.f. (Fig. 3D), y Rodriguezia sp., que corresponden al $4.3 \%$ de las especies estudiadas (Fig. 2A) y son parte de cuatro de los diez clados estudiados. Su porcentaje es variable (Fig. 2D); el clado con mayor porcentaje de especies con arenas es el $\mathrm{G}$ y el de menor es el $\mathrm{H}$; los clados A, B, C, D, F e I no tienen arenas (Fig. 2D). Cuitlauzina pygmaea presenta las arenas en las células epidérmicas a diferencia de las otras especies que los presentan en las células del mesófilo.

Rossioglossum ampliatum tiene conjuntos de cristales con crecimientos circulares concéntricos en las células epidérmicas (Fig. 2A, 2E,
3E); esta especie corresponde al clado J, para el que se reporta por primera vez esta forma cristalina.

Algunas pocas especies (4.3\%) (Fig. 2A) contienen agrupaciones formadas por placas cristalinas que pueden estar radialmente arregladas, que surgen de un núcleo central o a partir de un núcleo lateral. Ambas formas pueden permanecer juntas y estar localizadas en las células del mesófilo. Estas placas radiales se observaron por primera vez en Cuitlauzina candida (Lindl.) Dressler \& N.H.Williams, C. convallarioides (Schltr.) Dressler \& N.H.Williams (Fig. 3F), C. egertonii (Lindl.) Dressler \& N.H.Williams, C. pulchella (Bateman ex Lindl.) Dressler \& N.H.Williams y Miltonia spectabilis; que correspondieron a dos de los diez clados estudiados: el J con mayor porcentaje y el $\mathrm{G}$ con menor porcentaje de especies que los contienen (Fig. 2F). Sólo siete de los diez clados estudiados contienen cristales distintos a los rafidios; la proporción de especies entre los clados, para una forma particular de cristal es variada (Fig. 2A, Fig. 6). Los clados $\mathrm{G}$ y $\mathrm{J}$ se distinguen porque contienen prismas, drusas, arenas y placas radiales; los clados E y $\mathrm{H}$ comparten la presencia de prismas, drusas y arenas. Dentro de los clados, el F seguido por el E son los que tienen una mayor proporción de especies con prismas. Los clados F e I comparten la presencia de prismas y drusas; el clado B sólo presenta prismas, mientras que los clados A, C y D se caracterizan por no tener cristales distintos a los rafidios.

Para los géneros con varias especies estudiadas se encontró que todos ellos tienen rafidios. Sin embargo, con respeto a las otras formas cristalinas analizadas se observó que en la mayoría de las especies de Oncidium siempre están presentes los prismas y las drusas, mientras que en las de Comparettia, Cuitlauzina, Cyrtochilum y Otoglossum, solamente están presentes los prismas. Los géneros cuyas especies muestran la mayor variación respecto a la presencia de sus cristales son Cuitlauzina, Miltonia y Oncidium (Cuadro 2).

Estégmatos: En Oncidiinae los estégmatos son cónicos con superficie rugosa, generalmente 

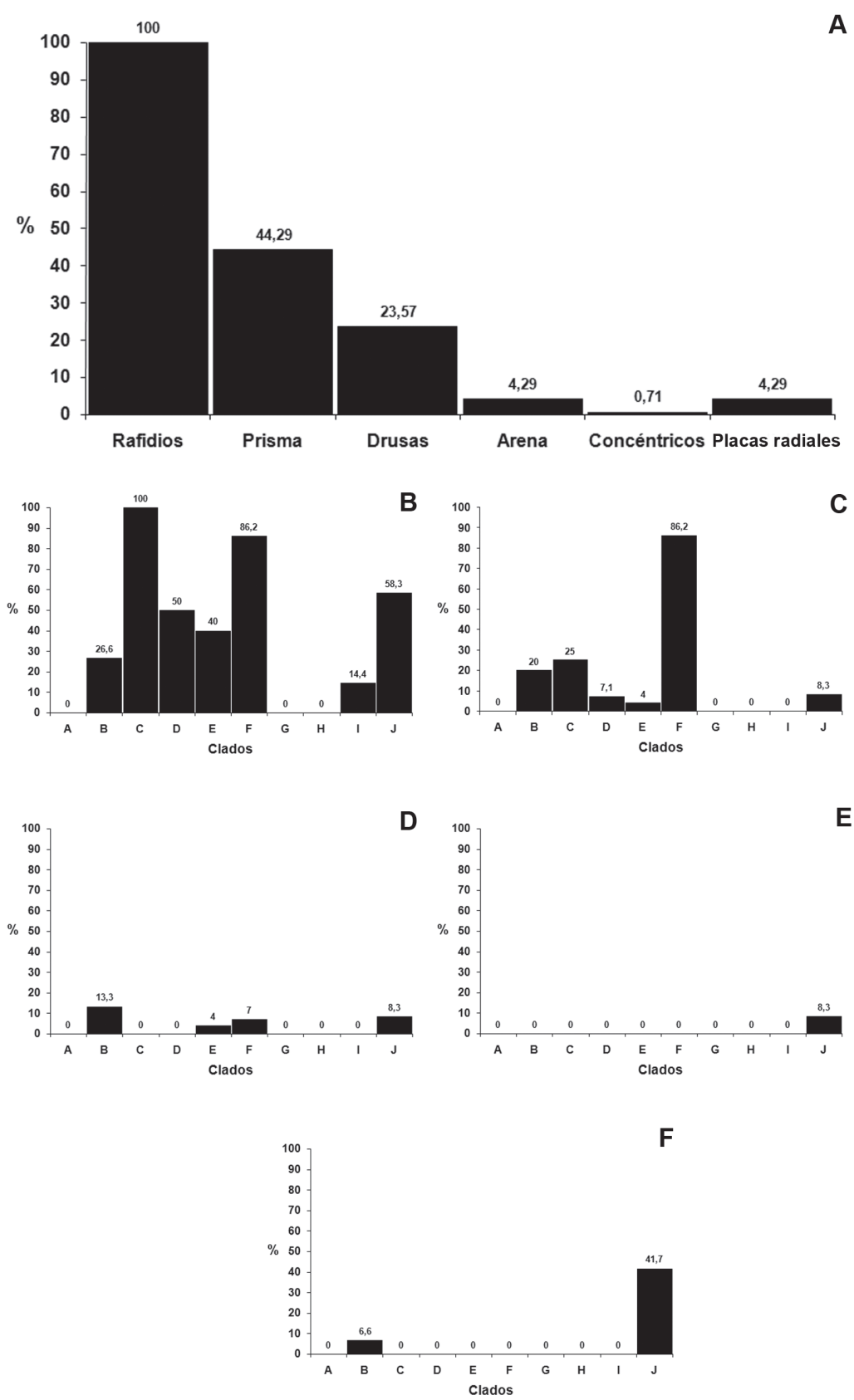

Fig. 2. Diversidad de cristales en Oncidiinae. A. Porcentaje de especies que presentan las diferentes formas cristalinas. B. Porcentaje de especies con prismas. C. Con drusas. D. Con arena. E. Con concéntricos. F. Con placas radiales.

Fig. 2. Diversity of crystals in Oncidiinae. A. Percentage of species with different forms of crystals. B. Percentage of species with prisms. C. Percentage of species with druses. D. Percentage of species with sand. E. Percentage of species with concentric. F. Percentage of species with radial plates. 

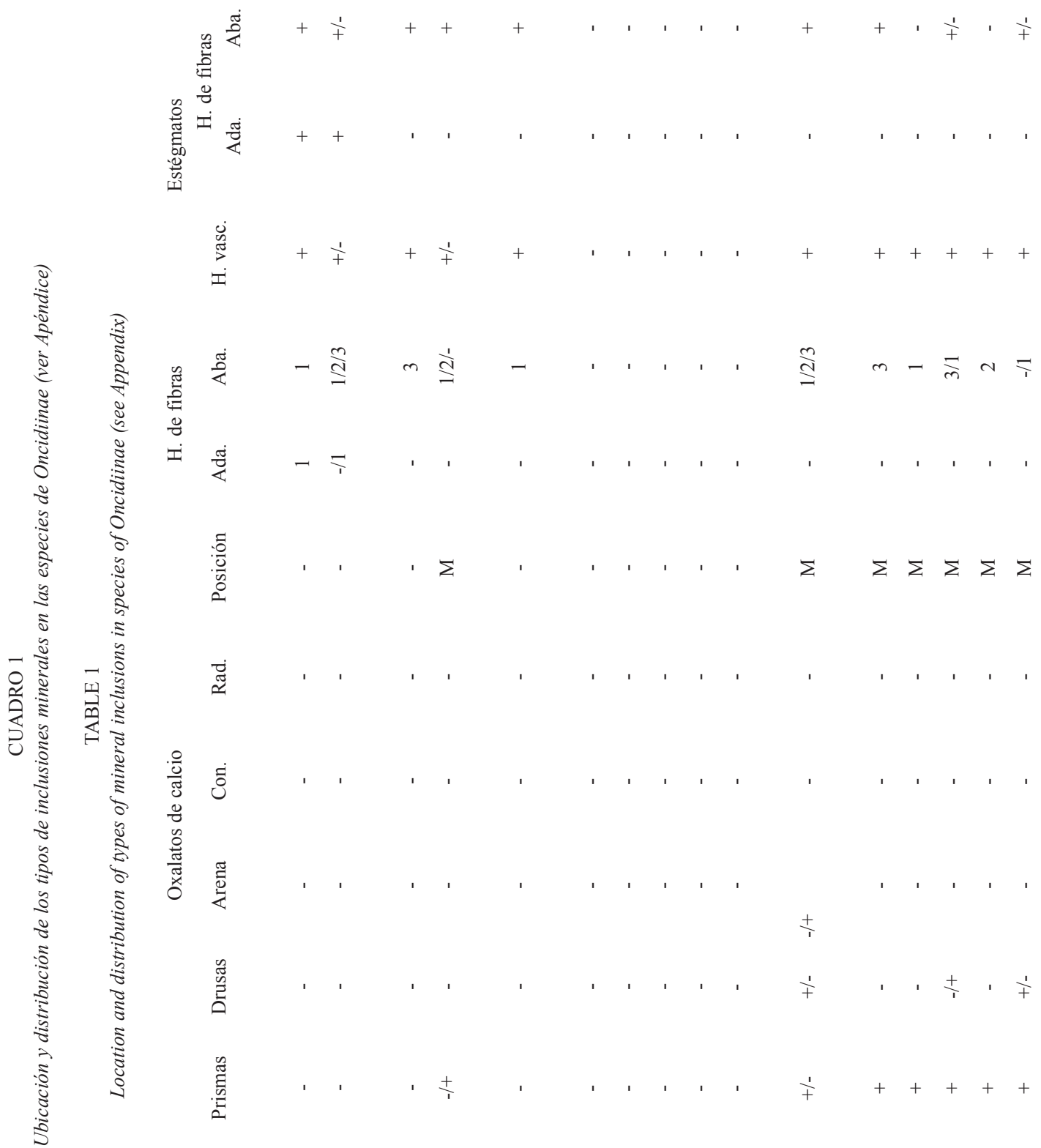

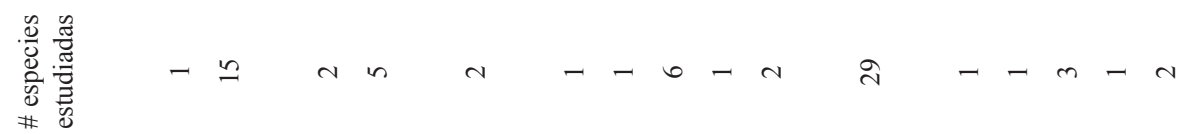

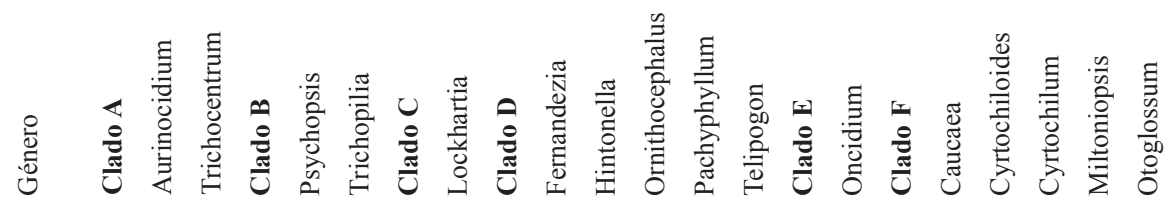




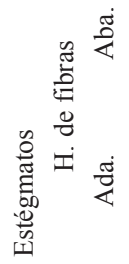

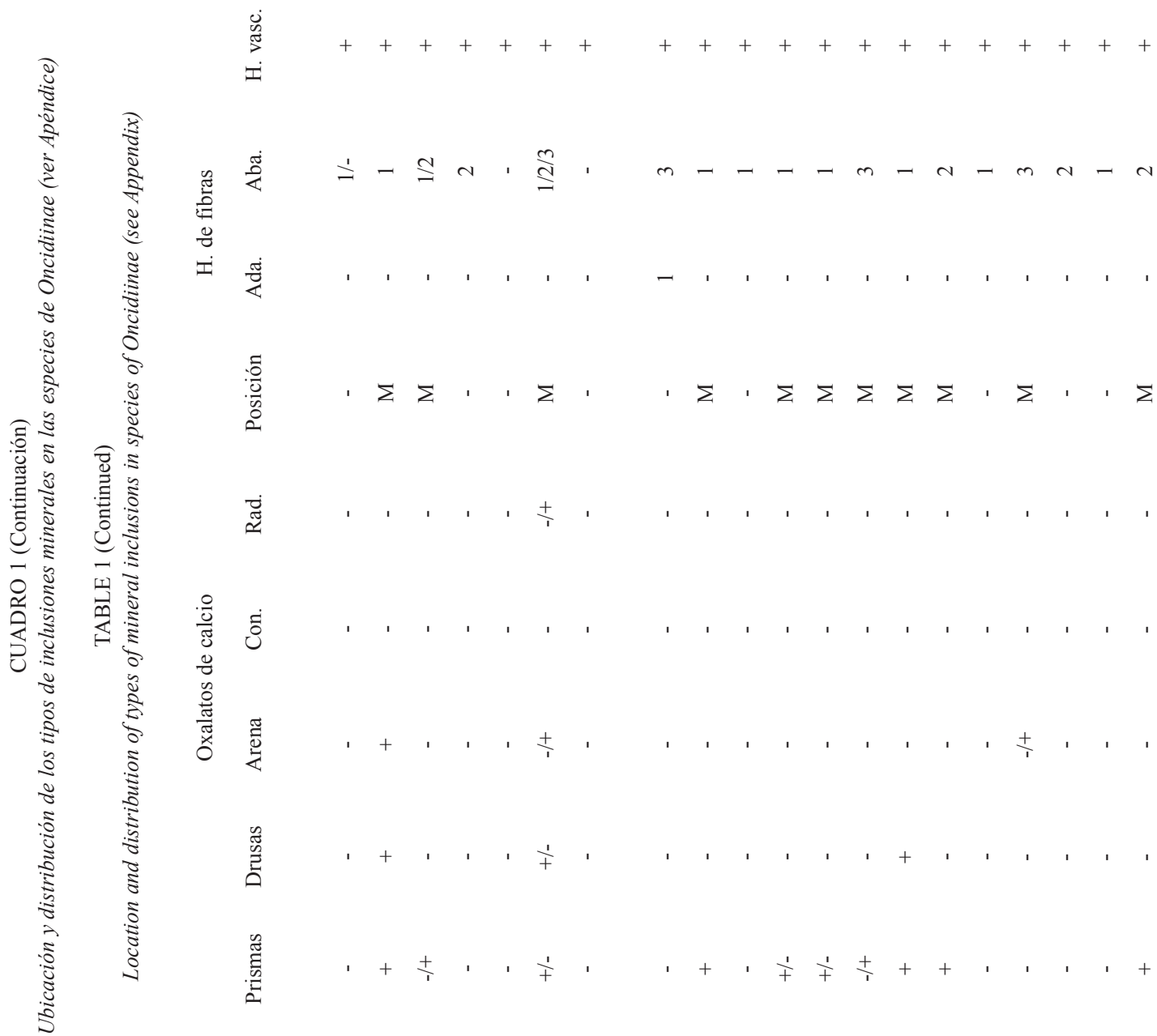

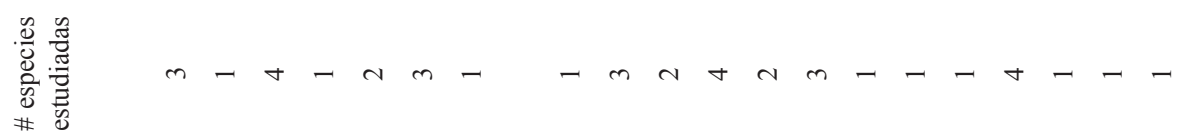

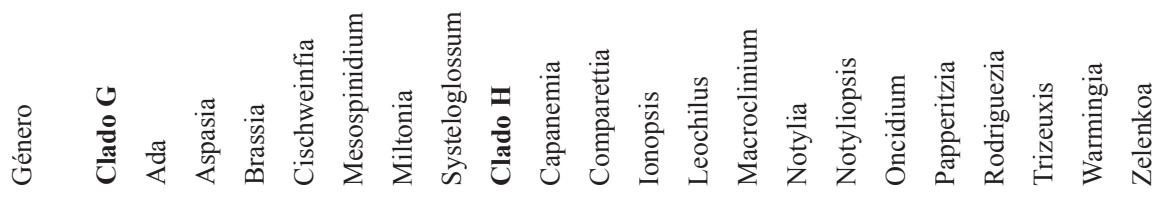




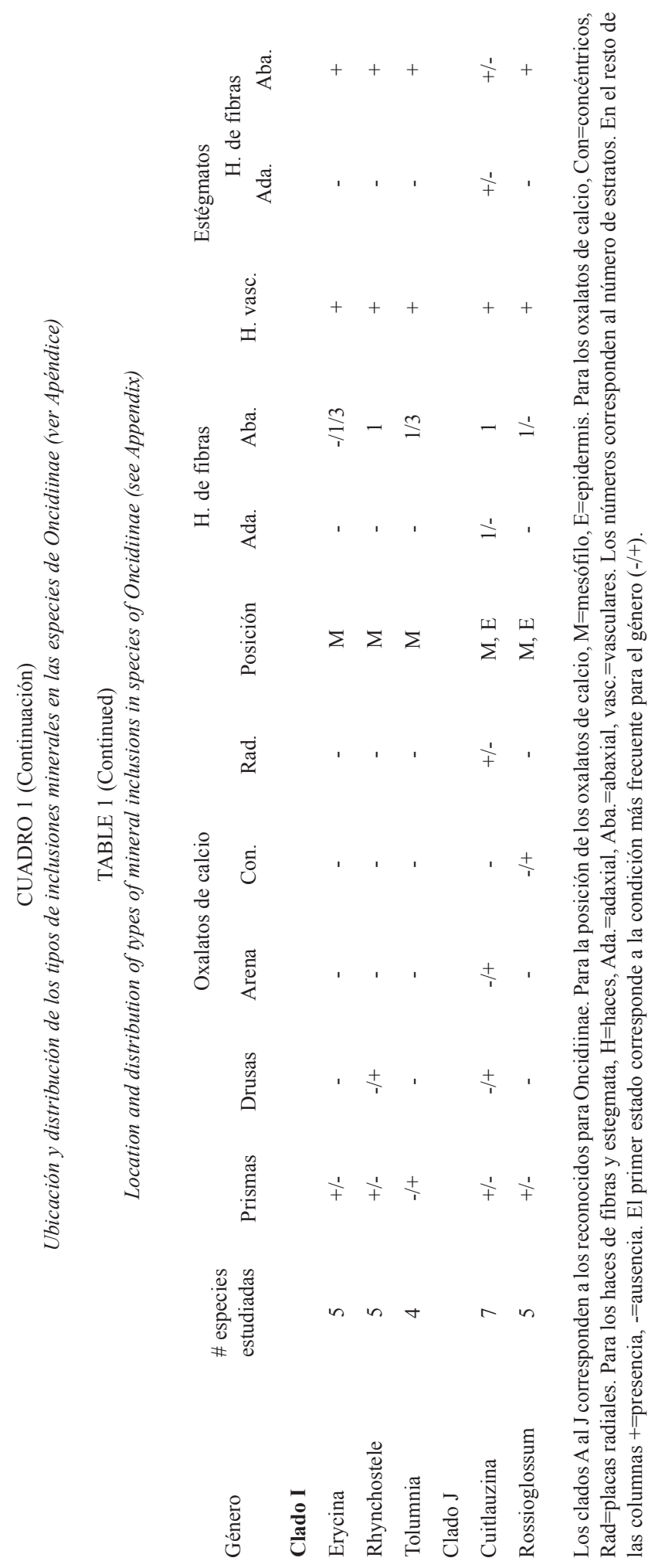




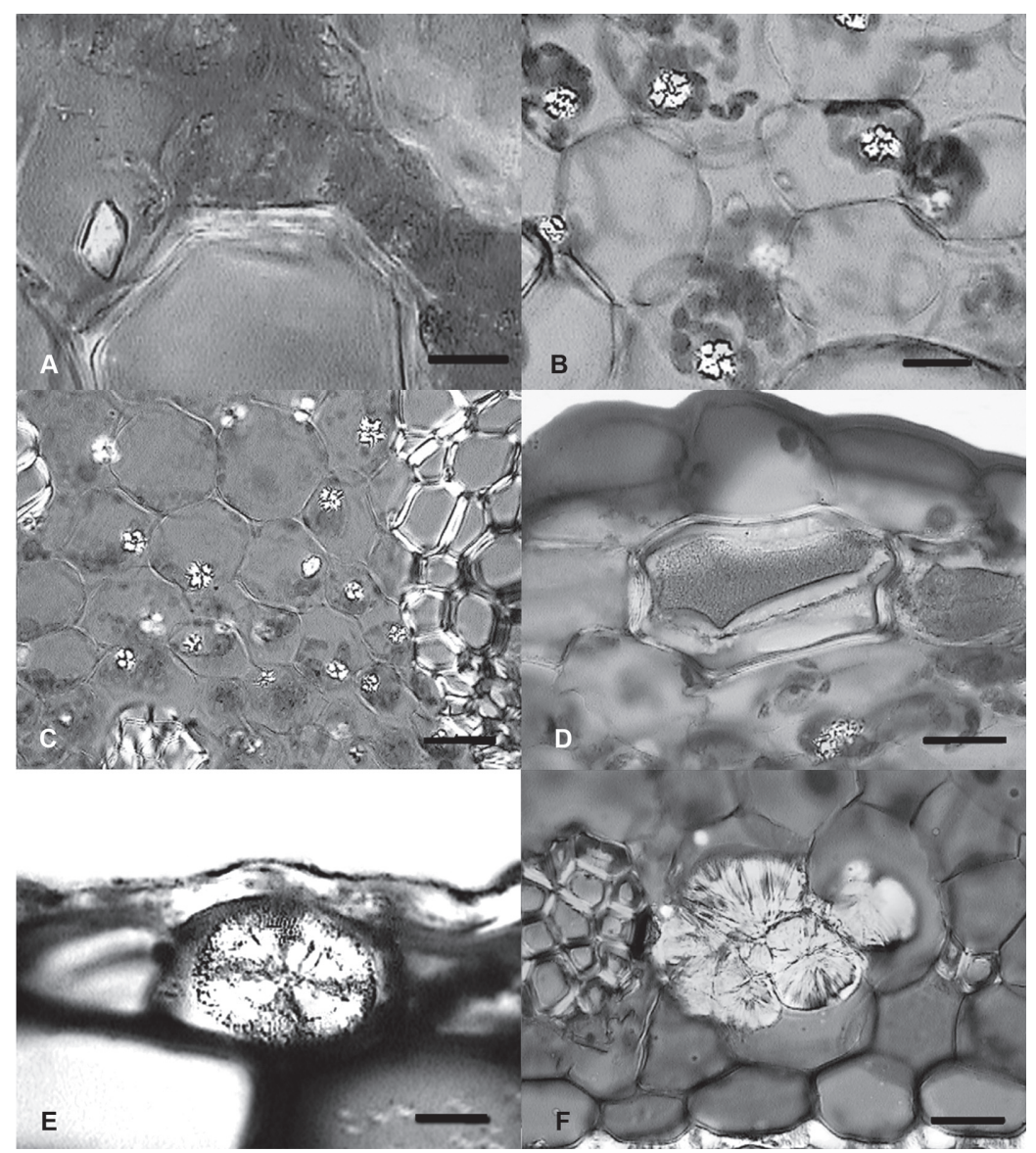

Fig. 3. Cristales en Oncidiinae. Secciones transversales, con luz polarizada. A. Prismas, Oncidium hymenanthum. B. Drusas, Oncidium oblongatum. C. Drusas, Oncidium ghiesbreghtianum. D. Arenas, Oncidium warmingii. E. Concéntrico, Rossioglossum ampliatum. F. Placas radiales, Cuitlauzina convalarioides. Barras $=1 \mu \mathrm{m}$.

Fig. 3. Crystals in Oncidiinae. Transversal sections, with polarized light. A. Prisms, Oncidium hymenanthum. B. Druses, Oncidium oblongatum. C. Druses, Oncidium ghiesbreghtianum. D. Sand, Oncidium warmingii. E. Concentric, Rossioglossum ampliatum. F. Radial plates, Cuitlauzina convalarioides. Bars $=1 \mu \mathrm{m}$.

formando hileras a lo largo de los haces vasculares y/o de los haces de fibras (Cuadro 1). Se observó que $89.3 \%$ de las especies estudiadas contienen estégmatos asociados a los haces vasculares (Fig. 4A, 5A, 5B; Cuadro 1). En los clados $\mathrm{C}, \mathrm{E}, \mathrm{F}, \mathrm{G}, \mathrm{H}$, I y $\mathrm{J}$ todas las especies tienen estégmatos en sus haces vasculares. Por otro lado, sólo algunas especies de los clados A y B tienen haces vasculares sin estégmatos, mientras que todas las especies del clado D tienen haces vasculares sin estégmatos (Fig. 4B). Entre los géneros con más de una especie estudiada, todos excepto Ornithocephalus, presentan estégmatos en sus haces vasculares; asimismo, la presencia de estégmatos es variable en Trichocentrum y Trichopilia (Cuadro 2).

El $75.4 \%$ de las especies tienen estégmatos asociados a los haces de fibras (Fig. 4A, 4C, 5C, 5D; Cuadro 1). Estos haces de fibras pueden tener una posición adaxial y/o abaxial (Fig. 4C, 5C). Notoriamente 12 especies que tiene haces de fibras adaxiales, todas tienen estégmatos y siempre se organizan en un estrato (Fig. 4C, 5D; Cuadro 1). Estas especies 
CUADRO 2

Diversidad de cristales y estégmatos en géneros con varias especies

TABLE 2'

Diversity of crystals and stegmata in genera with multiple species

Oxalatos de calcio

Género
Rafidios Prismas Drusas Arena Con. Rad.

Clado A

Trichocentrum (15)

Clado B

Psychopsis (2)

Trichopilia (5)

Clado C

Lockhartia (2)

Clado D

Ornithocephalus (6)

Clado E

Oncidium (29)

Clado F

Cyrtochilum (3)

Otoglossum (2)

Clado G

Ada (3)

Brassia (4)

Mesospinidium (2)

Miltonia (3)

Clado $\mathrm{H}$

Comparettia (3)

Ionopsis (2)

Leochilus (4)

Macroclinium (2)

Notylia (3)

Rodriguezia (4)

Clado I

Erycina (5)

Rhynchostele (5)

Tolumnia (4)

Clado J

Cuitlauzina (7)

Rossioglossum (5)

P

P A

P V

P

P

P

P V

$\mathrm{P}$

$\begin{array}{ll}\mathrm{P} & \mathrm{A} \\ \mathrm{P} & \mathrm{V}\end{array}$

P A

$\begin{array}{ll}\mathrm{P} & \mathrm{A} \\ \mathrm{P} & \mathrm{V}\end{array}$

A

A

$\begin{array}{ll}\text { A } & \text { A } \\ \text { A } & \text { A }\end{array}$

A A

$\begin{array}{ll}\text { A } & \text { A } \\ \text { V } & \text { V }\end{array}$

$\mathrm{A}$
$\mathrm{A}$
$\mathrm{V}$

$\begin{array}{ll}P & V \\ P & V \\ P & V\end{array}$

V

V A

A

A

$\mathrm{P}$
$\mathrm{P}$

$\begin{array}{lll}\text { A } & \text { A } & \text { P } \\ \text { A } & \text { A } & \text { P } \\ \text { A } & \text { A } & \text { P } \\ \text { A } & \text { V } & \text { P }\end{array}$

\begin{abstract}
$\begin{array}{lllll}\text { A } & \text { A } & \text { A } & \text { A } & \text { P }\end{array}$
\end{abstract}

$\begin{array}{lllllllll}\text { P } & \text { P } & \text { A } & \text { A } & \text { A } & \text { A } & \text { P } & \text { A } & \text { P } \\ \text { P } & \text { A } & \text { A } & \text { A } & \text { A } & \text { A } & \text { P } & \text { A } & \text { P } \\ \text { P } & \text { V } & \text { A } & \text { A } & \text { A } & \text { A } & \text { P } & \text { A } & \text { P } \\ \text { P } & \text { V } & \text { A } & \text { A } & \text { A } & \text { A } & \text { P } & \text { A } & \text { P } \\ \text { P } & \text { V } & \text { A } & \text { A } & \text { A } & \text { A } & \text { P } & \text { A } & \text { P } \\ \text { P } & \text { A } & \text { A } & \text { V } & \text { A } & \text { A } & \text { P } & \text { A } & \text { P }\end{array}$

Estégmatos

$\begin{array}{ccr}\text { Haz } & \text { Haces de fibras } \\ \text { vascular } & \text { Ada. Aba. }\end{array}$

$\begin{array}{lllllll}\text { V } & \text { A } & \text { A } & \text { A } & \text { A } & \text { P }\end{array}$

A $A \quad A \quad$ A

$P$
$P$
$P$

A

A

A

$\mathrm{P}$
$\mathrm{P}$
$\mathrm{P}$

$\begin{array}{lllll}\text { V } & \text { V } & \text { A } & \text { V } & \text { P } \\ \text { A } & \text { A } & \text { A } & \text { A } & \text { P }\end{array}$

$\begin{array}{ll}\mathrm{P} & \mathrm{P} \\ \mathrm{A} & \mathrm{P}\end{array}$

El número entre paréntesis corresponde a las especies estudiadas en cada género. $\mathrm{A}=$ ausencia, $\mathrm{P}=$ presencia, $\mathrm{V}=$ variable. 

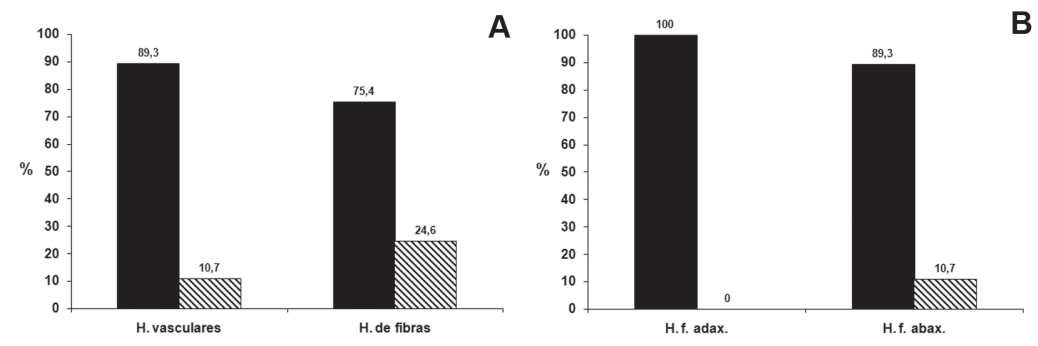

B

C

D
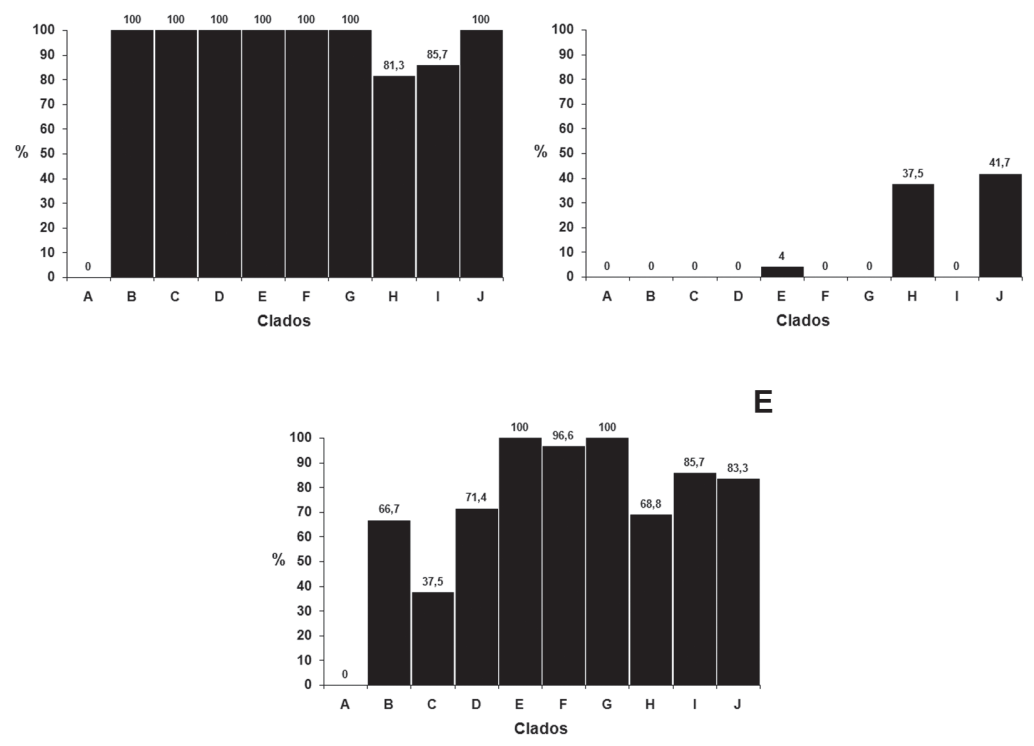

Fig. 4. Distribución de estégmatos en Oncidiinae y porcentaje de especies por clados con estégmatos (ver Apéndice). A. Haces vasculares y haces de fibras. B. Haces vasculares. C. Haces de fibras adaxiales y abaxiales (barra negra=presencia, barra con diagonales=ausencia). D. Haces de fibras adaxiales. E. Haces de fibras abaxiales.

Fig. 4. Distribution of stegmata in Oncidiinae and percentage of species by clades with stegmata (see Appendix). A. Vascular bundles and fibers bundles. B. In vascular bundles. C. Adaxial and abaxial fibers bundles. (black bar=presence, bar with diagonals=absence). D. In adaxial fibers bundles. E. In abaxial fibers bundles.

corresponden a los clados A, H y J (Fig. 4D). De las especies que tienen haces de fibras abaxiales, 89.3\% tienen estégmatos (Fig. 4C); excepto el clado D, los restantes nueve clados estudiados los presentan. Todas las especies del clado $\mathrm{C}$ y $\mathrm{H}$ siempre tienen estégmatos en estos haces, mientras que sólo $37.5 \%$ de las especies del clado $\mathrm{F}$ tienen estégmatos en sus haces de fibras abaxiales (Fig. 4E). Excepto
Ornithocephalus (clado D), Mesospinidium (clado G), Cyrtochilum y Otoglossum (clado F) y Trichocentrum (clado A), todos los géneros con más de una especie estudiada presentan estégmatos en sus haces de fibras abaxiales (Cuadro 2). La distribución de los haces de fibras abaxiales, cuando se presentan, muestran una gran variación. Se pueden encontrar en uno, dos o tres estratos (Cuadro 1). Los 


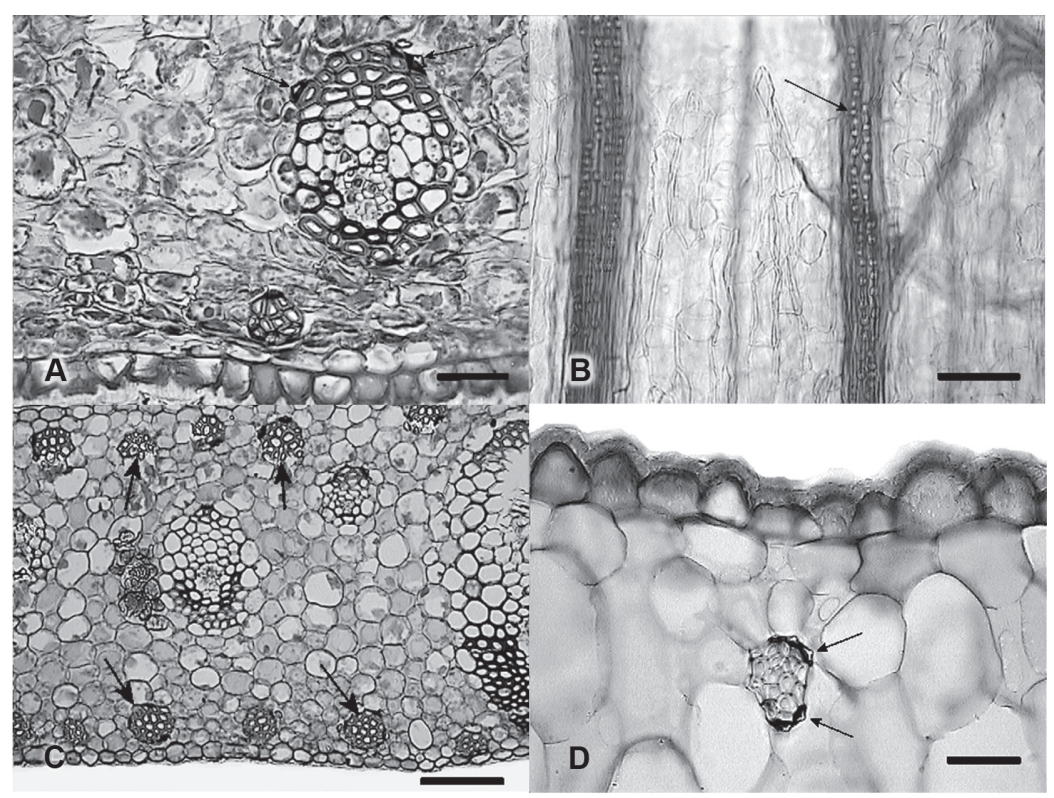

Fig. 5. Estégmatos en Oncidiinae. A. Haces vasculares, Cuitlauzina pendula (flechas), sección transversal. B. Haces vasculares, Ada glumacea (flecha), vista superficial. C. Haces de fibras adaxiales y abaxiales, Cuitlauzina egertonii (flechas), sección transversal. D. Haz de fibras adaxial, Aurinocidium pulvinatum (flechas), sección transversal. Barra en A, $\mathrm{D}=10 \mu \mathrm{m}$; en $\mathrm{B}, \mathrm{C}=50 \mu \mathrm{m}$.

Fig. 5. Stegmata in Oncidiinae. A. Vascular bundles, Cuitlauzina pendula (arrows), transversal section. B. Vascular bundles, Ada glumacea (arrow), superficial view. C. Adaxial and abaxial fiber bundles, Cuitlauzina egertonii (arrows), transversal section. D. Adaxial fiber bundle, Aurinocidium pulvinatum (arrows), transversal section. Bars in A, D=10 $\mu$ m; in $\mathrm{B}, \mathrm{C}=50 \mu \mathrm{m}$.

géneros con más de una especie estudiada de los clados C, H y J, más Psychopsis del clado $\mathrm{B}$, mantienen constante el número de estratos. Por otra parte, el número de estratos es variable en las especies de Ada, Brassia y Miltonia (clado G), Cyrtochilum (clado F), Erycina y Tolumnia (clado I), Oncidium (clado E), Trichocentrum (clado A) y Trichopilia (clado B) (Cuadro 1). Al examinar el número de estratos de los haces de fibras abaxiales y relacionarlos con la presencia de estégmatos, se encontró que los haces de fibras abaxiales distribuidos en un estrato con estégmatos están en 64 especies, los distribuidos en dos estratos se encontraron en 11 especies y los distribuidos en tres estratos están en 29 especies. No se encontró correlación significativa entre el número de estratos de haces de fibras abaxiales con estégmatos y el número de especies que los presentan $(-0.072$, $\mathrm{p}>0.05)$.

\section{DISCUSIÓN}

Cristales: Si bien los rafidios, estiloides y drusas se reportan como las tres formas cristalinas comunes para monocotiledóneas (Prychid \& Rudall 1999), sólo los rafidios están presentes en todas las especies estudiadas de Oncidiinae, los estiloides están ausentes, mientras que las drusas están presentes en algunas especies, principalmente del clado E. Esta subtribu se caracteriza por presentar una gran diversidad de formas cristalinas, como rafidios, prismas, drusas, arenas, concéntricos y placas radiales. Estas dos últimas formas son reportadas por 
primera vez para Oncidiinae y para Orchidaceae. Los cristales concéntricos son distintivos en la epidermis de Rossioglossum ampliatum. Las placas radiales son características de las hojas de Cuitlauzina, excepto C. pendula La Llave ex Lex. (clado J), aunque también se observaron en Miltonia spectabilis (clado G), lo que sugiere que se originaron temprano en la evolución de Oncidiinae (clado J) y de manera paralela, más adelante en uno de los clados derivados (clado G).

De acuerdo a Prychid \& Rudall (1999), la presencia de rafidios es un carácter común en las orquídeas, particularmente en las epífitas (Stern \& Carlsward 2004). Esto se cumple también en Oncidiinae ya que todas las especies estudiadas presentaron rafidios; aunque su forma es constante, su tamaño no lo es. Se les encuentra en las células del mesófilo de la hoja, a menudo en idioblastos cristalinos como en muchas otras monocotiledóneas (Rudall et al. 1998). El único reporte encontrado de rafidios a nivel de las células epidérmicas de la hoja para Orchidaceae es en Myoxanthus, carácter que permite distinguirlo de otros géneros de Pleurothallidinae (Pridgeon et al. 2001). El clado representado por Fernandezia-HintonellaOrnithocephalus-Pachyphyllum-Telipogon (D) y el clado Lockhartia (C), sólo presentan rafidios y este carácter fortalece su reconocimiento como clados hermanos (Sandoval-Zapotitla et al. en prensa). El clado Trichocentrum (A) también presenta esta condición, lo que es congruente con la hipótesis de que estos tres clados están cercanamente relacionados y tienen una posición basal en Oncidiinae (Fig. 6).

Los cristales prismáticos se presentan en los clados B, E, F, G, H, I y J de Oncidiinae (Fig. 6). La presencia de prismas en los clados basales B y J, sugiere que esta forma cristalina ya estaba presente desde los grupos ancestrales de la subtribu y se mantuvo en la evolución de Oncidiinae. La ausencia de prismas en los clados $\mathrm{C}$ y D puede ser una pérdida secundaria. Como un carácter constante, los cristales prismáticos están presentes en Caucaea, Cyrtochilum, Miltoniopsis y Otoglossum (clado F); su presencia es un carácter distintivo, aunque no exclusivo a ellos y apoya la propuesta de asumirlos como miembros del clado Cyrtochilum, reconocido por Williams et al. (2001a, 2001b) y Sandoval-Zapotitla et al. (en prensa). Además de éste, los clados con mayor abundancia de prismas son el clado Oncidium (E) donde un $86 \%$ de sus especies los contienen y el clado Cuitlauzina (J) (Sosa et al. 2001, Williams et al. 2001b) con un 58\%. Las especies de ambos clados habitan en climas fríos, en altitudes hasta los $3400 \mathrm{~m}$ y tienden a presentar una mayor proporción de prismas.

Las drusas, si bien son raras entre las monocotiledóneas, dentro de Orchidaceae sólo se han reportado en Dendrobium aloifolium (Blume) Rchb.f (Carlsward et al. 1997), en algunas especies de Rhynchostele (Rojas-Leal 1993, Soto et al. 1993) y en la subtribu Ponerinae de la subfamilia Epidendroideae (Cervantes 2009). En este trabajo se amplía a 12 el número de géneros de Oncidiinae que las presentan. Los resultados muestran que estos cristales son característicos de la mayoría de los miembros del clado Oncidium (E) (Fig. 6). Estas especies habitan en ambientes de frescos a fríos y se distribuyen en un intervalo de altitud que va de los 500 a los $3100 \mathrm{~m}$; asimismo, tienden a tener una mayor proporción de drusas y prismas. En menor proporción, las drusas también están presentes en algunas especies de los clados Cyrtochilum (F), Miltonia (G), Rodriguezia $(\mathrm{H})$, en el formado por ErycinaRhynchostele-Tolumnia (I), (Sandoval-Zapotitla et al. en prensa) y Cuitlauzina (Sosa et al. 2001, Williams et al. 2001b). Los miembros de los clados A, B, C y D no contienen drusas y su ausencia es significativa lo que apoya el reconocerlos como clados cercanamente relacionados (Fig. 6). Su presencia en una especie del clado J, sugiere que las drusas se originaron tempranamente en Oncidiinae. Por otro lado, su presencia en los clados derivados E, F, G, H e I (Sandoval-Zapotitla et al. en prensa) apoya el reconocerlos como clados cercanamente relacionados.

Los cristales en arena se presentan sólo en algunas especies de los clados E, G, H y J (Fig. 6). La presencia de cristales tipo arena en las 


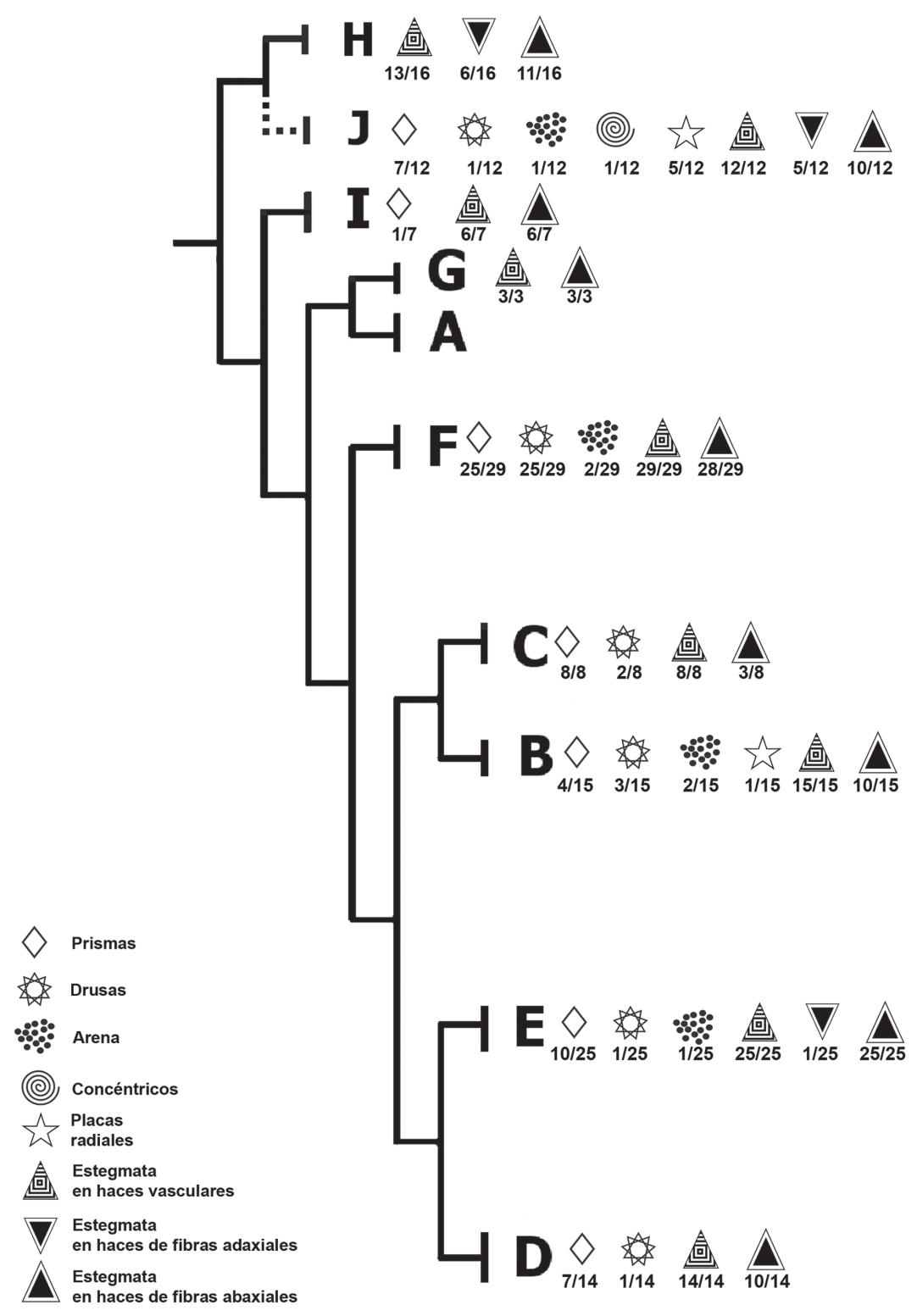

Fig. 6. Inclusiones minerales sin optimizar en la hipótesis filogenética para Oncidiinae modificada a partir de Sandoval et al. (en prensa).

Número superior=especies que contienen una forma particular de cristal. Número inferior= \# especies estudiadas por clado. La posición del clado J es asignada de acuerdo a la hipótesis filogenética para Oncidiinae propuesta por Williams et al. (2001b). Los rafidios están presentes en todas las especies estudiadas de Oncidiinae, por lo que no se muestran.

Fig. 6. Mineral inclusions are displayed without optimization in the phylogenetic hypothesis for Oncidiinae modified from Sandoval et al. (in press).

The upper number indicates the species that contain that particular kind of crystal and the lower indicates the number of species studied for each clade. The position of clade $J$ is assigned according to the phylogenetic hypothesis for Oncidiinae proposed by Williams et al. (2001b). Raphides are present in all species studied Oncidiinae therefore not shown. 
células epidérmicas de las hojas es exclusiva de Cuitlauzina pygmaea, miembro del clado basal Cuitlauzina (J); asimismo, se reportan por primera vez para Oncidiinae. La presencia de cristales en arena a nivel de las células del mesófilo es compartida en algunas especies de los clados E, G y F, reconocidos como clados derivados en Oncidiinae (Sandoval-Zapotitla et al. en prensa). Su presencia en una especie del clado $\mathrm{J}$ sugiere que las arenas se originaron tempranamente en la subtribu y más tarde, en forma independiente en otros clados dentro de Oncidiinae. La ausencia de estos cristales en los miembros del clado Cyrtochilum (F) y del clado Erycina-Rhynchostele-Tolumnia (I), también clados derivados, pudiera ser interpretada como una pérdida secundaria o una reversión ya que los clados A, B, C y D que se resuelven como basales (Sandoval-Zapotitla et al. en prensa), no los presentan. Dos de las especies de los clados E y G tienen arenas y sólo una de los clados $\mathrm{H}$ y $\mathrm{J}$ los presentan, lo que indica que esta forma de cristal es escasa en Oncidiinae.

Aún cuando se observó una diversidad de formas cristalinas dentro de la subtribu, su forma y ubicación es constante para algunos clados e incluso para algunos géneros. A nivel de clados, el clado F muestra constancia para los prismas y el clado E para prismas y drusas; los clados G y J son los más diversos, por lo que se sugiere estudiar un mayor número de especies. A nivel de género, Oncidium es constante en prismas y drusas. Dentro de algunos otros géneros las formas de cristales son variadas, por ejemplo Cuitlauzina, Miltonia y Oncidium presentan tres o más formas de cristales.

Excepto por el clado J que habita en ambientes fríos y presenta la mayor diversidad de formas cristalinas dentro de Oncidiinae, la mayoría de las especies de los clados A, B, C y $\mathrm{D}$ resueltos como basales (Sandoval-Zapotitla et al. en prensa), generalmente ocupan ambientes cálidos a templados. No obstante, algunos de los miembros del clado D (Telipogon y Pachyphyllum, que suman alrededor de 300 especies) habitan principalmente en ambientes fríos (bosques montanos) de América tropical. A partir de las especies estudiadas, se observó que estos clados basales tienden a mostrar una menor diversidad y abundancia de formas cristalinas. Por otro lado, los clados E, F, G, H e I resueltos como derivados (excepto algunas especies de los clados F e I), generalmente habitan ambientes templados a fríos y tienden a presentar una mayor diversidad y abundancia de formas cristalinas. Se requiere ampliar el muestreo de los géneros para verificar estas tendencias.

Estégmatos: Los estégmatos están presentes en la mayoría de las especies de Oncidiinae estudiadas. Estos resultados apoyan los registros de estégmatos para los miembros de la tribu Maxillarieae subfamlia Epidendroideae, a la cual pertenece Oncidiinae (Ayensu \& Williams 1972, Williams 1974, SandovalZapotitla 1993, Sandoval-Zapotitla \& Terrazas 2001, Stern \& Carlsward 2006). Sin embargo, es importante subrayar que varias especies de otras tribus y subtribus de Epidendroideae no presentan estégmatos (Prychid et al. 2004).

El clado D carece de estégmatos. La presencia de estégmatos en los haces vasculares $\mathrm{y}$ en los haces de fibras adaxiales y abaxiales es característico de los clados $\mathrm{A}$, J y $\mathrm{H}$; los dos primeros son clados basales, lo que indica que esta condición surgió tempranamente en la evolución de la subtribu (Fig. 6). El resto de los clados sólo tienen estégmatos en los haces vasculares y en los haces de fibras abaxiales, lo que pudiera significar que la ausencia de haces de fibras adaxiales y por lo tanto de estégmatos en esta posición, es un pérdida secundaria en los clados derivados de la subtribu. La presencia de haces de fibras adaxiales con estégmatos en uno de los miembros del clado $\mathrm{H}$, también derivado, pudiera representar una reversión desde los clados basales.

La mayoría de los clados de Oncidiinae tienen haces de fibras abaxiales con estégmatos, excepto el clado D; esto indica que tal condición es un carácter tempranamente derivado y común en la subtribu, y pudiera significar que ya estaba presente desde el ancestro de la subtribu. La ausencia de haces de fibras abaxiales con estégmatos en el clado D podría representar una pérdida secundaria (Fig. 6). 
Todas las especies del clado Lockhartia (C) y Rodriguezia $(\mathrm{H})$ tienen haces de fibras abaxiales con estégmatos; asimismo, la mayoría de las especies del clado Trichopilia (B), Oncidium (E), (Sandoval-Zapotitla et al. en prensa) y del clado Cuitlauzina (J) (Sosa et al. 2001, Williams et al. 2001b), también tienen haces de fibras abaxiales con estégmatos. La mayoría de las especies del clado $\mathrm{F}$ tienen haces de fibras abaxiales sin estégmatos; sin embargo, aún cuando las especies de este clado tienen hojas con características similares a las de las especies de los clados donde se presentan las fibras abaxiales con estégmatos, y que habitan en ambientes y altitudes similares, no los presentan. Se desconoce las condiciones micro-climáticas, así como los mecanismos involucrados en la fijación de dióxido de sílice y la formación de los estégmatos en las orquídeas; asimismo, se desconocen las ventajas adaptativas que tiene la presencia de estégmatos en las hojas de las orquídeas, particularmente los asociados a los haces de fibras, por lo que estos temas son necesarios de explorar.

A nivel de género, únicamente en Cyrtochilum y Otoglossum (F) se observó variabilidad entre sus especies respecto a los estégmatos de los haces de fibras abaxiales. En otros géneros la variabilidad se ve reflejada en la presencia de los haces de fibras. Por ejemplo, las cinco especies de Erycina (I), E. cristaga$l l i$ (Rchb.f.) N.H.Williams \& M.W.Chase, E. pumilio (Rchb.f.) N.H.Williams \& M.W.Chase y E. pusilla (L.) N.H.Williams \& M.W.Chase, no tienen haces de fibras abaxiales ni estégmatos. Esta condición confirma su cercana relación e integración como un subclado dentro del clado Erycina (I); E. echinata (Kunth) Lindl. y E. hyalinobulbon (La Llave \& Lex.) N.H.Williams \& M.W.Chase, que tienen haces de fibras abaxiales y estégmatos, condición que apoya la propuesta de reconocerlos como taxa hermanos dentro del clado Erycina (I) (Sandoval-Zapotitla et al. en prensa). Además, todas las especies de Erycina tienen haces vasculares con estégmatos. De 15 especies estudiadas de Trichocentrum (A), T. caloceras Endres \& Rchb.f., T. candidum Lindl., T. cavendishianum
(Bateman) M.W.Chase \& N.H.Williams, T. fuscum Lindl. y $T$. pfavii Rchb.f. no tienen haces de fibras abaxiales ni estégmatos. Otros autores confirman la variabilidad de este carácter en el género y registran a $T$. albococcineum Linden y a $T$. hoegei Rchb.f., sin haces de fibras ni estégmatos (Sandoval-Zapotitla \& Terrazas 2001, Stern \& Carlsward 2006). Por otro lado, T. caloceras, T. candidum y T. fuscum no tienen estégmatos sobre sus haces vasculares, por lo tanto Trichocentrum es variable para estos caracteres.

Los haces de fibra abaxiales en Miltoniopsis warscewiczii (Rchb.f.) Garay \& Dunst. (F) carecen de estégmatos; no obstante, están presentes en sus haces vasculares. Stern \& Carlsward (2006) reportan que Miltoniopsis roezlii (Rchb.f.) God.-Leb. no tiene haces de fibras; Miltoniopsis incluye seis especies, por lo que se requiere estudiar las cuatro especies restantes para concluir sobre la condición de este carácter en todo el género.

Cuitlauzina es un género con seis especies (Dressler \& Williams 2003, Chase et al. 2008). A excepción de $C$. pendula y $C$. pygmaea (Lindl.) M.W.Chase \& N.H.Williams, cuyas hojas no tienen haces de fibras adaxiales, las otras especies se caracterizan por tener haces de fibras adaxiales y abaxiales con estégmatos y haces vasculares también con estégmatos. Los estégmatos en este conjunto de especies están dispuestos en tres sitios distintos dentro de sus hojas, lo que representa una mayor cantidad de sitios de depósito de dióxido de sílice y formación de estégmatos. La constancia de esta condición sugiere que está genéticamente fija en Cuitlauzina.

Osmoglossum y Dignathe han sido transferidos a Cuitlauzina (Dressler \& Williams 2003, Chase et al. 2008). Además de su cercana relación (Sosa et al. 2001), la presencia de estégmatos en tres sitios y otros caracteres anatómico-foliares apoyan su transferencia a Cuitlauzina.

Particularmente relevante es la ausencia de estégmatos en los haces vasculares, así como en haces de fibras adaxiales, abaxiales $\mathrm{y}$ estégmatos en los miembros del clado D 
(Sandoval-Zapotitla et al. en prensa). La ausencia de estégmatos en las hojas de Hintonella mexicana Ames, Ornithocephalus inflexus Lindl. y Stellilabium sp., también fue reportado por Stern \& Carlsward (2006); estos últimos autores reportan que Telipogon pulcher Rchb.f. tiene estégmatos con cuerpos de sílice cónicos y superficie rugosas; no obstante, en este estudio se observó que T. costaricensis Schltr. no tiene estégmatos, lo que sugiere que es necesario hacer una revisión de este carácter en otras especies antes de definir la condición de estégmatos para el género. La ausencia de haces de fibras y de estégmatos también en sus haces vasculares en estos géneros, apoyan la propuesta de reconocerlos como miembros de un clado monofilético en Oncidiinae, como sugieren Sandoval-Zapotitla et al. (en prensa).

Este trabajo documenta de manera integral la diversidad de inclusiones minerales en la subtribu Oncidiinae. La presencia y ubicación de las diferentes formas cristalinas en Oncidiinae son caracteres que pueden ser de importancia en sistemática a diferentes niveles, por ejemplo clados, géneros o especies. Se definen y reportan los cristales concéntricos y las placas radiales como dos nuevas formas de cristales en Oncidiinae.

La presencia de estégmatos en los haces vasculares y los haces de fibras abaxiales es un carácter común en la mayoría de los clados de Oncidiinae, excepto el clado (D) FernandeziaHintonella-Ornitocephalus-Pachyhyllum-Telipogon. Estos caracteres al parecer surgieron temprano en la evolución de la subtribu y se han mantenido a lo largo de su diversificación. La presencia de estégmatos en los haces vasculares y haces de fibras es constante para la mayoría de los géneros con más de una especie estudiada, pero variable en los géneros Cyrtochilum, Otoglossum, Trichocentrum y Trichopilia. A medida que se re amplié la representatividad de Oncidiinae, se contará con más evidencias que permitan ampliar los conocimientos sobre las características, la importancia sistemática y adaptativa, así como la evolución de los contenidos minerales en Oncidiinae.

\section{AGRADECIMIENTOS}

La primera autora agradece al Postgrado en Ciencias Biológicas de la Universidad Nacional Autónoma de México (UNAM) por el apoyo otorgado para la realización de esta investigación y al CONACYT por la beca (No. 199595) otorgada para sus estudios de doctorado. El Jardín Botánico del Instituto de Biología, UNAM permitió el uso de su equipo e instalaciones para la realización del trabajo. El Jardín Botánico Lankester, Universidad de Costa Rica brindó facilidades para obtener material biológico y bibliográfico. Concepción Guzmán Ramos y Patricia Zendejas López apoyaron con la elaboración de las preparaciones histológicas, Bárbara Estrada brindó apoyo logístico. Alejandro Vallejo Zamora y Julio Cesar Montero apoyaron con la edición de imágenes. Finalmente, se agradece a cuatro revisores anónimos por sus valiosos comentarios y sugerencias.

\section{RESUMEN}

Las inclusiones minerales en las plantas, han sido utilizadas como herramientas de diagnóstico en la identificación taxonómica. Se analizaron y compararon las inclusiones minerales en las hojas de 140 especies de Oncidiinae (Epidendroideae: Orchidaceae). Las secciones transversales de hojas se observaron para describir las inclusiones minerales con el apoyo de la microscopía de luz en campo claro, contraste de fases y polarización. Los cristales generalmente están presentes en las células del mesófilo, y sólo dos especies los presentan en las células epidérmicas. Se encontraron cristales de oxalato de calcio de diferentes formas y depósitos de dióxido de sílice en forma de estégmatos. Las formas cristalinas más comunes son rafidios, prismas y drusas. Sin embargo, algunas especies tienen cristales en arena, concéntricos o en placas radiales. En esta investigación se reportan las dos últimas por primera vez para Oncidiinae y también para Orchidaceae. Los estégmatos son cónicos con superficie rugosa, generalmente formando hileras a lo largo de las fibras. Comúnmente se presentan en los haces vasculares y en los haces de fibras abaxiales. Sin embargo, existen especies cuyos haces de fibras no tienen estégmatos, así como especies sin haces de fibras ni estégmatos. Se discute la importancia taxonómica de estas inclusiones minerales para los diferentes clados, géneros y/o especies de Oncidiinae.

Palabras clave: hoja, cristales, oxalatos de calcio, rafidios, sílice, estégmatos, Orchidaceae, Oncidiinae. 


\section{REFERENCIAS}

Ayensu, E.S. \& N.H. Williams. 1972. Leaf anatomy of Palumbina and Odontoglossum subgenus Osmoglossum. Amer. Orchid Soc. Bull. 41: 687-696.

Barrera, E.H. \& R.R. Cárdenas. 1997. El Microscopio Óptico. Universidad Nacional Autónoma de México, Campus-Iztacala, México, D.F. México.

Carlsward, B.S., W.L. Stern, W.S. Judd \& T.W. Lucansky. 1997. Comparative leaf anatomy and systematics in Dendrobium sections Aporum and Rhizobium (Orchidaceae). Int. J. Plant. Sci. 158: 332-342.

Cervantes, L.M. 2009. Estudio de la anatomía foliar de la subtribu Ponerinae (Orchidaceae, Epidendroideae) en un contexto filogenético. Tesis de Maestría, Universidad Nacional Autónoma de México, D.F. México, México.

Chase, M.W. \& J.D. Palmer. 1988. Chloroplast DNA variation, geographical distribution and morphological parallelism in subtribe Oncidiinae (Orchidaceae). Am. J. Bot. 75: 163-164

Chase, M.W., N.H. Williams, K.M. Neubig \& W.M. Whitten. 2008. Taxonomic transfers in Oncidiinae to accord with Genera Orchidacearum, Volume 5. Orchids 21: 20-31.

Chase, M.W., N.H. Williams \& W.M. Whitten. 2009. Oncidiinae Nomenclature. Generic changes in Genera Orchidacearum. Volume 5. Orchids 12: 228-238.

Davies, K. 1999. A preliminary survey of foliar anatomy in Maxillaria. Lindleyana 14: 126-135.

Dressler, R. 1993. Phylogeny and Classification of the Orchid Family. Dioscorides Press, Oregon. EEUU.

Dressler, R. \& N.H. Williams. 2003. New combinations in Mesoamerican Oncidiinae (Orchidaceae). Selbyana 24: 44-45.

Franceschi, V.R. \& H.T. Horner Jr. 1980. Calcium oxalate crystals in plants. Bot. Rev. 46: 361-427.

Franceschi, V.R. \& P.A. Nakata. 2005. Calcium oxalate in plants: Formation and function. Ann. Rev. Plant. Biol. 56: 41-71.

Hodson, M.J., P.J. White, A. Mead \& M.R. Broadley. 2005. Phylogenetic variation in the silicon composition in plants. Ann. Bot. 96: 1027-1046.

Horner, H.T. \& B.L. Wagner. 1995. Calcium oxalate crystal formation in higher plants, p. 53-72. In S.R. Khan.
Calcium Oxalate in Biological Systems. CRC, Boca Raton, Florida, EEUU.

Lersten, N.R. \& H.T. Horner. 2000. Calcium oxalate crystal types and trends in their distribution patterns in leaves of Prunus (Rosaceae: Prunoideae). Plant. Syst. Evol. 224: 83-96.

Møller, J.D. \& H. Rasmussen. 1984. Stegmata in Orchidales: Character state distribution and polarity. Bot. J. Linn. Soc. 89: 53-76.

Pridgeon A.M., R. Solano \& M.W. Chase. 2001. Phylogenetic relationships in Pleurothallidinae (Orchidaceae): combined evidence from nuclear and plastid DNA sequences. Am. J. Bot. 88: 2286-2308.

Prychid, C.J. \& P.J. Rudall. 1999. Calcium oxalate crystals in monocotyledons: A review of their structure and systematics. Ann. Bot. London 84: 725-739.

Prychid, C.J., P.J. Rudall \& M. Gregory. 2004. Systematics and biology of silica bodies in monocotyledons. Bot. Rev. 69: 377-440.

Rincón, S.A. \& N. Reyes. 1991. Manual de Microscopía Óptica. Asociación de Químicos del Instituto Nacional de la Nutrición Salvador Zubirán, D.F. México, México.

Rojas-Leal, A. 1993. Anatomía foliar de Lemboglossum Halbinger (Orchidaceae: Oncidiinae) y géneros relacionados. Tesis de licenciatura, Universidad Nacional Autónoma de México, D.F. México, México.

Rudall, P.J, M.W Chase, D.F. Cutler, J. Rusby \& A. Bruijn. 1998. Anatomical and molecular systematics of Asteliaceae and Hypoxidaceae. Bot. J. Linn. Soc. 127: $1-42$

Sandoval-Zapotitla, E. 1993. Anatomía foliar de Cuitlauzina pendula. Orquídea (Méx.) 13: 181-190.

Sandoval-Zapotitla, E. \& T. Terrazas. 2001. Leaf anatomy of 16 taxa of the Trichocentrum clade (Orchidaceae: Oncidiinae). Lindleyana 16: 81-93.

Sandoval-Zapotitla, E., A. Rojas, C. Guzmán, L. Carmona, R.M. Ponce, C. León, C. Loyola, M.A. Vallejo \& A. Medina. 2005. Técnicas Aplicadas al Estudio de la Anatomía Vegetal. Cuadernos del Instituto de Biología, Universidad Nacional Autónoma de México, D.F. México, México.

Sandoval-Zapotitla, E., J. García-Cruz, T. Terrazas \& J.L. Villaseñor. 2010. Relaciones filogenéticas de la subtribu Oncidiinae (Orchidaceae) inferidas a partir de caracteres estructurales y moleculares (ITS y matK): un enfoque combinado. En prensa. 
Solereder, H. \& F.J. Meyer. 1930. Systematische Anatomie der Monokotyledonen. VI Microspermae. Gebrüder Borntraeger, Berlin (English translation, 1969, Israel Program for Scientific Translations, Jerusalem).

Sosa, V., M.W. Chase, G. Salazar, W.M. Whitten \& N.H. Williams. 2001. Phylogenetic position of Dignathe (Orchidaceae: Oncidiinae): evidence from nuclear ITS ribosomal DNA sequences. Lindleyana 16: 94-101.

Soto, M.A., G.A. Salazar \& A. Rojas. 1993. Nomenclatural changes in Rhynchostele, Mesoglossum, and Lemboglossum (Orchidaceae, Oncidiinae). Orquídea (Méx.) 13: $145-152$

Stern, W.L. 1997a. Vegetative anatomy of subtribu Oncidiinae (Orchidaceae). Bot. J. Linn. Soc. 124: 121-136.

Stern, W.L. 1997b. Vegetative anatomy of subtribu Habenariinae (Orchidaceae). Bot. J. Linn. Soc. 125: 211227

Stern, W.L. \& B.S. Carlsward. 2004. Vegetative constants in the anatomy of epiphytic orchids. Orchid Rev. 112: 119-122.

Stern, W.L. \& B.S. Carlsward. 2006. Comparative vegetative anatomy and systematics of Oncidiinae (Maxillarieae, Orchidaceae). Bot. J. Linn. Soc. 152: 91-107.

Stern, W.L. \& W.S. Judd. 2001. Comparative anatomy and systematics of Catasetinae (Orchidaceae). Bot. J. Linn. Soc. 136: 153-178.
Stern, W.L., M. Morris, W.S. Judd, A.M. Pridgeon \& R.L. Dressler. 1993. Comparative vegetative anatomy and systematics of Spiranthoideae (Orchidaceae). Bot. J. Linn. Soc. 113: 161-197.

Vovides, A.P. 1999. Microscopía Óptica para las Ciencias Biológicas. Serie Ciencias Naturales. Universidad de Ciencias y Artes del Estado de Chiapas, Tuxtla Gutiérrez, México.

Webb, M.A. 1999. Cell-mediated crystallization of calcium oxalate in plants. Plant Cell. 11: 751-761.

Williams, N.H. 1974. The value of plant anatomy in orchid taxonomy, p. 281-298. In M. Ospina. Proceedings of the Seventh World Orchid Conference. Medellin, Colombia.

Williams, N.H., M.W. Chase, T. Fulcher \& W.M. Whitten. 2001a. Molecular systematics of the Oncidiinae based on evidence from four DNA sequence regions: expanded circumscriptions of Cyrtochilum, Erycina, Otoglossum, and Trichocentrum and a new genus (Orchidaceae). Lindleyana 16: 113-139.

Williams, N.H., M.W. Chase \& W.M. Whitten. 2001b. Phylogenetic positions of Miltoniopsis, Caucaea, a new genus, Cyrtochiloides, y Oncidium phymatochilum (Orchidaceae: Oncidiinae) based on nuclear and plastid DNA sequence data. Lindleyana 16: 272-285.

Yukawa, T. \& W.L. Stern. 2002. Comparative vegetative anatomy and systematic of Cymbidium (Cymbidieae: Orchidaceae). Bot. J. Linn. Soc. 138: 419. 


\section{APÉNDICE \\ Lista de especies de Oncidiinae incluidas en este trabajo \\ APPENDIX \\ List of species Oncidiinae including in this work}

El material revisado proviene de colecciones institucionales, como la Asociación Mexicana de Orquideología (AMO); Jardín Botánico Francisco Javier Clavijero, Xalapa, Veracruz, México; Jardín Botánico Lankester, Cartago, Costa Rica (JBL). Colecciones particulares de Alexander Rojas (AR), Andrés Vovides (AV), Weimann Bussey (WB), C. Javier García Cruz (JGC), Diego Bogarín (DB), Eduardo A. Pérez García (EAP), Elvira Yañes Guerrero (EYG), Eric Hágsater (EH), Estela Sandoval Zapotitla (ESZ), Franco Pupulin (FP) Gerardo A. Salazar (GAS), Ignacio AguirreOlavarrieta (IA), Juan José Zúñiga (JJZ), Jorge Lamas Walz (JLW), Miguel Ángel Soto Arenas (MAS), Oscar Francke (OF), Pesach Lubinsky (PL), Philip J. Brewster (PJB), R. Leleu (RL), Rafael Valverde (RAVA), Robert Dressler (RD), Rolando Jiménez Machorro (RJM), Sandro Cusi (SC), Teodoro Platas Hernández (TPH) y Harry Zelenko (HZ).

\begin{tabular}{|c|c|c|c|}
\hline $\begin{array}{l}\text { Especie } \\
\text { Clado A }\end{array}$ & Referencia & Especie & Referencia \\
\hline $\begin{array}{l}\text { Aurinocidium pulvinatum (Lindl.) } \\
\text { Romowicz \& Szlach. }\end{array}$ & EH Hort & C. confertum (Rchb.f.) Dalström & $R D$ Hort \\
\hline $\begin{array}{l}\text { Trichocentrum andreanum (Cogn.) R. } \\
\text { Jiménez \& Carnevali }\end{array}$ & ESZ 003 & C. macranthum (Lindl.) Kraenzl. & $S C$ Hort \\
\hline $\begin{array}{l}\text { T. ascendens (Lindl.) M.W. Chase \& N.H. } \\
\text { Williams }\end{array}$ & RJM 857 & $\begin{array}{l}\text { Miltoniopsis warszewiczii (Rchb.f.) Garay } \\
\text { \& Dunst. }\end{array}$ & $J B L 2908$ \\
\hline $\begin{array}{l}\text { T. bicallosum (Lindl.) M.W. Chase \& N.H. } \\
\text { Williams }\end{array}$ & MAS 3236 & $\begin{array}{l}\text { Otoglossum chiriquense (Rchb.f.) Garay } \\
\text { \& Dunst. }\end{array}$ & MAS Hort \\
\hline T. caloceras Endres \& Rchb.f. & RAVA 510 & $\begin{array}{l}\text { O. globuliferum (Kunth) N.H. Williams \& } \\
\text { M.W. Chase }\end{array}$ & FP 5296 \\
\hline T. candidum Lindl. & GAS 5123 & Clado G & \\
\hline $\begin{array}{l}\text { T. cavendishianum (Bateman) M.W. Chase } \\
\& \text { N.H. Williams }\end{array}$ & GAS 4707 & Ada aurantiaca Lindl. & JBL 2968 \\
\hline $\begin{array}{l}\text { T. cebolleta (Jacq.) M.W. Chase \& N.H. } \\
\text { Williams }\end{array}$ & EAP 286 & $\begin{array}{l}\text { A. chlorops (Endres \& Rchb.f.) N.H. } \\
\text { Williams }\end{array}$ & $J B L 13452$ \\
\hline $\begin{array}{l}\text { T. flavovirens (L.O. Williams) M.W. Chase } \\
\& \text { N.H. Williams }\end{array}$ & $R L$ Hort & A. glumacea (Lindl.) N.H. Williams & EH 8819 \\
\hline T. fuscum Lindl. & $O F$ Hort & Aspasia epidendroides Lindl. & $W B$ Hort \\
\hline $\begin{array}{l}\text { T. luridum (Lindl.) M.W. Chase \& N.H. } \\
\text { Williams }\end{array}$ & EH Hort & Brassia arcuigera Rchb.f. & $J B L 3758$ \\
\hline $\begin{array}{l}\text { T. microchilum (Bateman ex. Lindl.) M.W. } \\
\text { Chase \& N.H. Williams }\end{array}$ & EH 4286 & B.caudata (L.) Lindl. & OF Hort \\
\hline T. pfavii Rchb.f. & RAVA 512 & B. signata Rchb.f. & MAS 4399 \\
\hline T. splendidum (A.Rich. ex Duch.) M.W. & $M A S$ Hort & B. verrucosa Bateman ex Lindl. & ESZ 28 \\
\hline
\end{tabular}




\section{APÉNDICE (Continuación) \\ Lista de especies de Oncidiinae incluidas en este trabajo}

APPENDIX (Continued)

List of species Oncidiinae including in this work

\author{
Especie \\ T. stramineum (Bateman ex Lindl.) M.W. \\ Chase \& N.H. Williams \\ T. teres (Ames \& C.Schweinf.) M.W. Chase \\ $\&$ N.H. Williams
}

\section{Clado B}

Psychopsis krameriana (Rchb.f.) H.G.Jones

P. papilio (Lindl.) H.G. Jones

Trichopilia maculata Rchb.f.

T. marginata Henfr.

T. suavis Lindl.

T. tortilis Lindl.

T. turialbae Rchb.f.

\section{Clado C}

Lockhartia amoena Endres \& Rchb.f.

L. oerstedii Rchb.f.

L. oerstedii Rchb.f.

\section{Clado D}

Fernandezia tica Mora-Ret. \& García-

Castro

Hintonella mexicana Ames

Ornithocephalus bicornis Lindl. ex Benth.

O. inflexus Lindl.

O. iridifolius Rchb.f.

O. lankesteri Ames

O. tripterus Schltr.

$O$. sp.

\section{Referencia}

JGC 668

Especie

Cischweinfia dasyandra (Rchb.f.) Dressler \& N.H. Williams

RAVA Hort Mesospinidium horichii I.Bock

M. panamense Garay

JBL 13825 Miltonia candida Lindl.

MAS Hort M. phymatochila (Lindl.) N.H. Williams \& M.W. Chase

JBL 11683 M. spectabilis Lindl.

JBL 11273 Systeloglossum acuminatum Ames \& Schweinf.

JBL $03130 \quad$ Clado H

MAS 4822 Capanemia superflua (Rchb.f.) Garay

RAVA Hort

Comparettia falcata Poepp. \& Endl.

C. macroplectron Rchb.f. \& Triana

JBL 07707 Comparettia tuerckheimii (Schltr.) M.W. Chase \& N.H. Williams

DB 9399

Ionopsis satyrioides (Sw.) Rchb.f.

MAS 2787 I. utricularioides (Sw.) Lindl.

Leochilus carinatus (Knowles \& Westc.) Lindl.

$R D 6706$

L. crocodiliceps (Rchb.f.) Kraenzl.

$S C$ Hort

L. oncidioides Knowles \& Westc.

DB 144

L. tricuspidatus (Rchb.f.) Kraenzl

TPH 265

Macroclinium bicolor (Lindl.) Dodson

TPH 311

M. lexarzanum (Hágsater \& R. González) Dodson

HZ Hort Notylia barkeri Lindl.

MAS $4978 \quad$ N. leucantha Salazar

BJL $8870 \quad$ N. orbicularis A. Rich. \& Galeotti
Referencia

RAVA Hort

FP 5357

$J B L 1661$

MAS Hort

$H Z$ Hort

MAS Hort

DB 2664

OF Hort

EAP 391

$R D$ Hort

MAS 4922

OF Hort

$R J M$ Hort

ESZ 46

ESZ 45

GAS Hort

$J J Z$ Hort

MAS 4951

ESZ 10

ESZ 17

IAO 1193

ESZ 8 


\section{APÉNDICE (Continuación)}

Lista de especies de Oncidiinae incluidas en este trabajo

APPENDIX (Continued)

List of species Oncidiinae including in this work

Especie

Pachyphyllum hispidulum (Rchb.f.) Garay \& Dunst.

T. costaricensis Schltr.

Telipogon erratus (Dressler) N.H. Williams \& Dressler

\section{Clado E}

Oncidium alexandrae (Bateman) M.W. Chase \& N.H. Williams

O. brachyandrum Lindl.

O. cirrhosum (Lindl.) Beer

O. constrictum (Lindl.) Beer

O. cheirophorum Rchb.f.

O. epidendroides (Kunth) M.W. Chase \& N.H. Williams

O. fimbriatum Lindl.

O. ghiesbreghtianum A. Rich. \& Galeotti

O. heteranthum Poepp. \& Endl.

O. hintonii L.O. Williams

O. hymenanthum (Schltr.) M.W. Chase \& N.H. Williams

O. leleui R.Jiménez \& Soto Arenas

O. leucochilum Bateman ex Lindl.

O. luteo-purpureum (Lindl.) Beer

O. karwinskii (Lindl.) Lindl.

O. marshallianum Rchb.f.

O. minaxoides( Kraenzl.) M.W. Chase \& N.H. Williams
Referencia Especie

DB $2716 \quad$ Notyliopsis beatricis P. Ortiz

Referencia

$J B L$ Hort

AR Hort Oncidium flexuosum Lodd.

MAS Hort

JBL 11856 Papperitzia leiboldii (Rchb.f.) Rchb.f.

RJM 1422

Rodriguezia compacta Schltr.

JJZ Hort

MAS $6401 \quad$ R. dressleriana R.González

GAS 2092

EAP 155 R. lanceolata Ruiz \& Pav.

OF Hort

EH $8879 \quad$ R. sp.

MAS Hort

JBL 2070 Trizeuxis falcata Lindl.

$J B L$ Hort

MAS 5587 Warmingia zamorana Dodson

$J B L$ Hort

$R D$ Hort

Zelenkoa onusta (Lind1.) M.W. Chase \& N.H. Williams

$H Z$ Hort

\section{$M A S$ Hort Clado I}

MAS $4101 \quad$ Erycina cristagalli (Rchb.f.) N.H. Williams \& M.W. Chase

EH $8275 \quad$ E. echinata (Kunth) Lindl.

ESZ 13

ESZ $011 \quad$ E. hyalinobulbon (La Llave \& Lex.) N.H. Williams \& M.W. Chase

JJZ Hort E. pumilio (Rchb.f.) N.H. Williams \&

RD 6669 M.W. Chase

ESZ 012 E. pusilla (L.) N.H. Williams \& M.W. Chase

$R J M$ Hort

MAS 3565 Rhynchostele beloglossa (Rchb.f.) Dressler \& N.H. Williams

MAS Hort R. bictoniensis (Bateman) Soto Arenas \& Salazar

RJM $770 \quad$ R. maculata ((La Llave \& Lex.) Soto MAS 4500 Arenas \& Salazar

MAS Hort $\quad$ R. madrensis (Rchb.f.) Soto Arenas \& Salazar

EH 8917 R. londesboroughiana (Rchb.f.) Soto Arenas \& Salazar
MAS 4374

GAS 2648

MAS 2197
TPH 283 


\section{APÉNDICE (Continuación)}

Lista de especies de Oncidiinae incluidas en este trabajo

APPENDIX (Continued)

List of species Oncidiinae including in this work

\begin{tabular}{|c|c|c|c|}
\hline Especie & Referencia & Especie & Referencia \\
\hline O. oblongatum Lindl. & GAS 4774 & Tolumnia guttata $(\mathrm{L}.) \mathrm{Nir}$ & $J B L 11413$ \\
\hline $\begin{array}{l}\text { O. oliganthum (Rchb.f.) L.O. Williams ex } \\
\text { Correll }\end{array}$ & MAS 3310 & T. pulchella (Hook.) Raf. & JBL 11677 \\
\hline O. ornithorhynchum Kunth & $R J M 626$ & T. triquetra (Sw.) Nir & $J B L 11680$ \\
\hline O. pictoides M.W. Chase \& N.H. Williams & $J J Z$ Hort & T. variegata (Sw.) Braem & RJM 969 \\
\hline O. planilabre Lindl. & $S C$ Hort & Clado J & \\
\hline O. praetextum Rchb.f. & MAS Hort & $\begin{array}{l}\text { Cuitlauzina candida (Lindl.) Dressler \& } \\
\text { N.H. Williams }\end{array}$ & MAS 3496 \\
\hline $\begin{array}{l}\text { O. reichenheimii (Linden \& Rchb.f.) Garay } \\
\& \text { Stacy }\end{array}$ & OF Hort & $\begin{array}{l}\text { C. convallarioides (Schltr.) Dressler \& } \\
\text { N.H. Williams }\end{array}$ & EYG Hort \\
\hline O. sphacelatum Lindl. & ESZ 018 & $\begin{array}{l}\text { C. egertonii (Lindl.) Dressler \& N.H. } \\
\text { Williams }\end{array}$ & MAS 2862 \\
\hline O. uniflorum Booth ex Lindl. & MAS 6425 & $\begin{array}{l}\text { C. egertonii (Lindl.) Dressler \& N.H. } \\
\text { Williams }\end{array}$ & $R L$ Hort \\
\hline O. varicosum Lindl. & $M A S$ Hort & C. pendula La Llave ex Lex. & $M A S 4208$ \\
\hline O. warmingii Rchb.f. & EH 11147 & $\begin{array}{l}\text { C. pulchella (Bateman ex Lindl.) Dressler } \\
\text { \& N.H. Williams. }\end{array}$ & MAS 1952 \\
\hline O. wentworthianum Bateman ex Lindl. & GAS 2301 & $\begin{array}{l}\text { C. pygmaea (Lindl.) M.W. Chase \& N.H. } \\
\text { Williams }\end{array}$ & EH 5181 \\
\hline Clado F & & $\begin{array}{l}\text { Rossioglossum ampliatum (Lindl.) M.W. } \\
\text { Chase \& N.H. Williams }\end{array}$ & $J L W$ Hort \\
\hline $\begin{array}{l}\text { Caucaea phalaenopsis (Lindl. ex Rchb.f.) } \\
\text { N.H. Williams \& }\end{array}$ & EH 10527 & R. grande (Lindl.) Garay \& G.C. Kenn. & GAS Hort \\
\hline M.W. Chase & & $\begin{array}{l}\text { R. krameri (Rchb.f.) M.W. Chase \& N.H. } \\
\text { Williams }\end{array}$ & RAVA Hort \\
\hline $\begin{array}{l}\text { Cyrtochiloides ochmatochila (Rchb. f.) } \\
\text { N.H. Williams \& M.W. Chase }\end{array}$ & RJM 2394 & $\begin{array}{l}\text { R. oerstedii (Rchb.f.) M.W. Chase \& N.H. } \\
\text { Williams }\end{array}$ & EH 6356 \\
\hline $\begin{array}{l}\text { Cyrtochilum cimiciferum (Rchb.f.) } \\
\text { Dalström }\end{array}$ & EH 10535 & $\begin{array}{l}\text { R. schlieperianum (Rchb.f.) Garay \& G.C. } \\
\text { Kenn. }\end{array}$ & RAVA 504 \\
\hline
\end{tabular}


